only 12 have been classified as simple. If these 12 could be analyzed it would be found that many of them should be classified with the blood cysts. Simple serous cysts are exceedingly rare. The danger of splenectomy is a great deal larger in those cases in which the spleen is functionating than it is when the function has disappeared. In the case reported by Dr. Bryan the cyst and spleen together weighed two and a half pounds, but there was not more than one and a half ounces of real spleen tissue.

DR. B. B. DAvis stated that he has looked over the literature on removal of the spleen and in practically all the cases of splenectomy done on animals for experimental purposes and cases of splenectomy done for rupture, the operation has been universally followed by a decrease in the reds. 'In the few cases in which splenectomy has been followed by an increase in the reds there has been some reason for it. In a case reported by Harris some years ago the condition had been present for years. In such cases Dr. Davis believes that the vicarious function carried on by the bone marrow becomes established and this affoets the blood formation. He said that if Dr. Harris will look up the literature he will find that it will bear out the statement that the removal of the spleen does reduce the number of red blood cells. The very fact that in these cases, in which there has been a careful study beforehand, the removal of the spleen has been followed by restoration to health shows that the splenomegaly is the primary lesion. It will not be possible to put this class of cases along with the case of which Dr. Jepson spoke. In primary splenomegaly there is a secondary cirrhosis of the liver, and ascites. Operation should be done in these cases before these complications arise, as the patients are very likely not to be helped by the operation.

\section{ACID INTOXICATION, AND LATE POISONOUS EFFECTS OF ANESTHETICS.}

HEPATIC TOXEMIA. ACUTE FATTY DEGENERATION OF THE LIVER FOLLOWING CHLOROFURM AND ETHER ANESTHESIA.*

ARTHUR DEAN BEVAN, M.D., AND

HENRY BAIRD FAVILL, M.D., CHICAGO.

In January, 1905, there occurred in our practice a case of gangrenous ovarian cyst with twisted pedicle. The patient was operated on and the case terminated fatally four days and a half later. The clinical picture was a very unusual one. Although we were aided in the conduct of the case by four consultants, a gynecologist, an internist, a neurologist, and a pathologist of more than ordinary ability, no definite diagnosis of the cause of the singular symptoms could be made. The parents of the child, fortunately, were intelligent and considerate and, realizing the importance to humanity and to science of ascertajning the exact cause of death, as the first step to the prevention of a similar result in other cases, permitted a postmortem examination. This was made with the greatest thoroughness, gross, microscopic and bacteriologic, and yet even then the cause of death was obscure and remained so until a careful review of the literature enabled us to collect twenty-nine more or less scattered cases, either identical or very similar to our own, in the light of which we believe the diagnosis becomes clear. We have found also certain comparatively recent experimental work reported, which assists materially in the understanding of the case.

\section{DR. FAVILI'S REPORT OF CASE.}

We shall cite first the outline of our experience,

* Read in the Section on Surgery and Anatomy of the American Medical Association, at the Fiffy-sixth Annual Session, July, 1905 which it seems worth while to report, first, because of its essential importance as a positive clinical picture; second, because of its value with respect to negative demonstrations.

Patient.-A girl, aged $12 \frac{1}{2}$ years, with the stature of a woman and the mental development of a girl of 16 or 18 . Not at all a "freak," but simply a noticeably handsome, well-developed and intelligent girl. She menstruated at the age of $11 \frac{1 / 2}{2}$ and was reasonably regular thereafter.

History.-Her history as to illness is negative. At 3 she had an acute otitis media which was treated by puncture, under chloroform, and recovered promptly and permanently; since that time no illness of any consequence, though she was of a lithemic type.

January 17: She came home from skating, complaining of great pain in the lower abdomen. Her menstruation being due, though it was habitually painless, her pain was ascribed to that fact. The pain was very severe. When seen two hours later it was somewhat less, but still severe. Temperature, 98.4; pulse, 72 ; general abdominal tenderness, but absolutely no local increase. The appendix was excluded and the conclusion as to premenstrual pain adopted. Some whiskey was given her, which she vomited.

A nurse was called; the child was covered with a flaxseed poultice on the lower abdomen, given small doses of phenacetin at intervals and saline cathartics.

January 18: In the morning her temperature was normal, but she was still in some pain. Temperature in the evening was 99 . She had a comfortable day and began to menstruate at $11 \mathrm{p} . \mathrm{m}$.

January 19: Thursday was an uneventful day; very little pain, no abdominal distension and very little tenderness; the bowels moved twice slightly; temperature at $5 \mathrm{p} . \mathrm{m}$. was 99. She vomited some orange juice at noon; she was cheerful and feeling well, howerer.

January 20: Friday she was still in pain; temperature, 100.5. Inasmuch as the menstrual conditions did not seem to justify any increase of symptoms, suspicion was aroused; a blood count slowed 11,600 leucocytes. Dr. Bevan was called in consultation. Temperature gradually rose and slight tenderness developed in the neighborhood of the appendix. At 2 o'clock the temperature was 102.2, leucocytes 14,000. Free bowel movement. At $9 \mathrm{p}$. $\mathrm{m}$. the temperature was 102.6 , pulse 108, leucocytes 16,500 . Dr. Webster was called in consultation.

A diagnosis of appendicitis was fully agreed on and an oper. ation was performed about midnight.

Previous to the operation a thorough pelvic examination was made bi-manually by rectum, but no palpable abnormality was found.

operation.-The operation was performed under chloroform, and it is noteworthy that it took a long time and an unusually large amount of chloroform to establish anesthesia. The exact amount of ehloroforn, however, was not noted at the time, but it is clear that in both respects the anesthesia was noticeable.

Because of some rather definite sense of resistance under the right rectus muscle, just above the pubes, the incision was made through the right rectus. The peritoneal cavity was opened and the appendix was found injected and buried in lymph directly under the incision. It was removed and the stump invaginated in the ordinary way. On separating the coils of intestines which surrounded the appendix, a black mass was seen. At first glance this was thought to be a gangrenous bowel, but on separating the intestines a gangrenous ovarian cyst and tube of the left side were brought into view. The intestines in contact with the mass were covered with a thin layer of lymph. There was no pus. The pedicle was ligated proximally to the point of torsion and the dead mass removed; the abdomen was closed without drainage. No time was lost in any way, and although the exact time was not noted, the operation was a rather short one.

Postoperative History.-From the time of operation till death, the dressings were not removed from the wound. The abdomen was flat, soft and painless, and there were absolutely no evidences of peritonitis. 
The patient was returned to bed in excellent condition; temperature 101.6, pulse 102 , and thoroughly conscious at 1:45 a. $\mathrm{m}$. The succeeding hours were unusually comfortable. The temperature steadily fell until Saturday at 11 a. m., when it was 99.8 ; pulse 86 ; respiration 23 , and leucocytes 12,000. The patient had a very comfortable day; temperature 101.2 at 4 p. m.; she romited a trifle at 7 p. m., and flatus was expelled freely.

January 22: Sunday, at 8 a. m., the temperature was 98.0 : pulse 100. She slept more or less during the night, vomited a little and passerl sereral slight stools. She complained of fceling hungry. She continued in this comfortable way all day Sunday. At $7 \mathrm{p}$. m. temperature was 99.2, pulse having risen to 112 , and the mother noticed that the patient was not quite natural in her remarks. The attention of the physicians was called to this point, but the incident was so slight as to seem unimportant to them. At $11 \mathrm{p}$. $\mathrm{m}$. the physicians were again ealled. The child was talking incolerently and exhibiting evidences of very great fright.

The picture of this mental condition is so unusual and from comparison with the experiences of others so typical that we venture to dilate on it. First, its appearance almost out of a elear sky. The child had been phenomenally favorable in her progress until forty-four hours after the operation. Second, the element of fright as the initial manifestation. Third, the rapid lapse into incoherence and unremitting delirium. Her first noticeable departure from the normal was at 3 p. $m$. on Sunday, and at 11 p. m. she gave the last obvious recognition of anybody. From that time on it was a series of alternations between sleep and delirium, more or less talkative, with a curious shrieking outery. The delirium was controllable to a certain extent by small amounts of morphin hyporlermatically, but except for that nothing seemed to affect her condition.

Consultation with Dr. Patrick.-Of course, the question of septic meningitis arose immediately. At noon on Monday, January 23, Dr. Patrick was invited into consultation. It that time there were present the following significant signs: Considerable muscular rigidity, exaggerated tendon reflexes, particularly patellar, ankle clonus and a perfectly marked Babinsky's reaction. Nevertheless, the consultation did not result in a clear diagnosis of meningitis.

Dr. Iugh T. Patrick's Statement.-From a neurologic standpoint the case presented several interesting and very instructive features.

First, the very early appearance of delirium without other symptoms of profound intoxication, and with no signs of organic disease. The rather quiet delirium of the confusional sort, with no definite tendency to depression or exaltation; no definite type of delusion or hallucination enabled one to $\mathrm{ex}$ clude all of the ordinary. psychoses. The varying indifference to surroundings, the occurrence of relatively lucid moments, and the well-marked impairment of recognition of time, location and personality placed the ease in the class of toxic psychosis or delirium, as delirium tremens, Korsakoff's psychosis. Absence of all signs of gross organic disease allowed the provisional exclusion of meningitis, or brain abscess, consequently, a diagnosis of toxic delirium was made; source of toxemia undetermined.

Second, the appearance of ankle clonus and Babinski's sign or "extensor response" with corroborative evidence of gross lrain or cord disease, was confusing. As is well known, Babinski's (or Collier's) sign indicates a lesion of the pyramidal tract. It is not to be elicited in every case of disease of this tract, but its presence in typical form is almost indubitable evidence of such disease. It is known, too, that this sign may be found in acute lesions, even a very few minutes after cerebral thrombosis or hemorrhage. Combined with delirium, another cerebral symptom, it would be taken to indicate a lesion or lesions of the cortex or subcortical tissue. Ankle clonus is also indicative of a Iesion of the pyramidal tract, but is exceedingly rare in acute diseases, such as hemorrhage, thrombosis, inflammation. Occasionally it is found in rigid or hypertonic states due to compression of the motor cortex, as in meningeal hemorrhage. I do not recall having seen it well defined in acute meningitis, though I sup- pose it might be possible. So far as I know, neither Babinski's sign nor ankle clonus has been reported as due to intoxication witliout gross, or well advanced, microscopic disease. The eye grounds were negative.

Consultation with Dr. Billings.-Monday aftermoon Dr. Pillings was invited into consultation. The conditions were about the same, except that the pulse was stendily going up, and the temperature slightly, being 101.0, the pulse 130 and the respirations 21 . There was also more or less suspicion of endocarditis and pericarditis, and it wils suspected that the sepsis had invaded the carliac structures.

Dr. Billings' Statement.-The symptoms indicated profound intoxication. There was coma, with marked congestion of the skin and of the mucous membranes, with moderate cyanosis and rapid heart action, irregular respirations, relaxed sphincter ani and retention of urine. At regular intervals a period of excitement, practically a convulsion, would oecur, lasting one minute or perhaps longer. 'This was manifested by a deeper redness of the skin and mucous membranes, a tonic contraction of all the voluntary muscles, by gradually increasing respiration, both in number and depth of chest morements, by stertor, by a tumultuous beating of the heart, by dilatation of the pupils and, at times by escape of the fluid contents of the rectum. The tonic contractions of the muscies occurred with the extremities extended and the head drawn slightly backward, with the neck muscles rigil. In the carly stages the forearms were alternately flexed and extended with the hands elosed. The stage of excitement was followed by a longer period of quiet. Juring this time the respirations were quiet, slow, shallow and almost imperceptible. The heart beat rapidly, but not as forcibly as during the stage of excitement. The muscles were relaxed, the pupils cqual and molerately wide. Physical examination of the chest showed no abnormal Inng findings. The lieart showed evidence of dilatation. The apex beat was displaced to the left and was diffuse. The left border dullness was one inch to the left of the nipple line, the base to the second rib, and the right border one inch to the right of the right sternal border. During the early stage no murmurs were heard. Soon a loud apical and basic systolic murmur conld be heard during the period of excitement. During the last day systolic murmurs could be heard at all times and during the convulsive period, with the tumultuous beating of the heart loud churning murmurs were heard. During the last day a distinet to-and-fro friction could be plainly, heard over the base of the heart. There can be no doubt that acute dilatation of the heart occurred. Postmortem contraction and rigidity of the heart muscle of course does not negative this statement.

Termination of Case.-The prostress on the following day, Tuesday, was uneventful, the pulse remaining ligh much of the time, the temperature varying between 99.4 and 101.8, respirations between 22 and 28 . Cheyne-Stokes respiration was present. The conditions continued without material change until Wednesday morning, when the temperature gradually began to rise; the pulse became very irregular and rapid, and finally death ensued at 2 o'clock, 110 hours after. operation.

\section{AUTOPSY.}

The postmortem examination made by Dr. Hektoen at the expiration of seven hours revealed the following facts:

Anatomic Diagnosis.-Recent laparotomy; wound removal of vermiform appendix and of left ovary and tube; local purulofibrinous peritonitis about field of operation; retrocecal ecchymosis; thrombus of left ovarian vein; fatty changes in the liver; swollen spleen; chronic nephritis (minimum degree), with acute degeneration; nultiple ecchymoses; edema and congestion of lungs; acute bronchitis; chronic fibrous peritonitis about right tube and ovary. Nenstruation.

Macroscopic Examination. - The boly is that of a well-developed, well-nourished girl. It is still warm and rigor-mortis is beginning. There is a recent sutured incision with normal margins to the right of the median line, beginning on a level with the navel and running down about 10 centimeters.

The general abdominal cavity is empty; in the pelvic portions there is some turbid blood; the omentum, ileum, cecum and sigmoid are matted together by a fibrinous exudate in the 
pelvis and behind the incision, the upper inner part of which is gaping, the margins here appearing somewhat soft and yellowish. The vermiform appendix is absent, the stump closed and water tight, with yellowish margins. The left tube and ovary are absent, the stump being sutured, the margins soft and yellowish. The left ovarian vein is closed by a red, quite firm, adherent clot. The right tube and ovary are embedded in firm, fibrous athesions and flattened out beyond recognition against the bladder and wall of the pelvis. There is a large area behind the cecum sparsely infiltrated with blood.

The pleural and pericardial cavities are empty and smoothly lined. The lungs are somewhat congested and edematous, especially posteriorly. There is no bronchitis. The heart contains some blood; the endoeardium is smooth; the muscle is firm; the intima of the aorta, vena cava and iliacs is smooth.

The spleen is large and quite firm; the Malpighian bodies are large and distinct. The liver is universally yellow, with no lobular centers; it is quite firm and larger than normal. The stomach is normal, with some softenings of the mucosa and some ecchymoses. The kidneys are large and firm, the capsules atherent in a few small places, the cortex thicker than normal, the markings not distinct; ecchymoses are present in the pelvis. The urinary bladder is normal; there are some eccliymoses in the mucosa.

The brain and its membranes are normal.

Microscopic Examination.-Kidneys: There are some chronic fibrous changes as shown by partial or complete obliteration of an occasional glomerulus and some, though slight, increased thickness of the eapsules of many glomeruli. The most striking change is the presence of large amounts of granular material (coagulated serum) in the cavities of the glomeruli visibly compressing many of the tufts. The cells lining Bowman's capsules are not much changed. The convoluted tubules are filled with a similar granular material, while the epithelial cells are well preserved. There is marked congestion of the vessels.

Liver: There is an advanced fatty change at the peripheries of the lobules. The central portions are congested, the columnar arrangement of the liver cells is thrown into disorder.

Spleen: This organ shows great congestion; the follicles are cellular.

Lungs: There is great congestion in the posterior parts of the lower lobes; here the cells contain many blood corpuseles, some being crowded. Some of the bronchioles are filled with lencocytic exudate.

Heart: The heart shows no changes.

Internal Margins of $\Lambda$ bdominal Incision: There is marked congestion and leucocytic infiltration, but no demonstrabie bacteria.

Left Ovarian Vein: A recent red thrombus is present. There are no bacterial masses.

Bacteriologic Examination.--Two flasks of broth and two of ascites broth inoculated with 1.5 c.c. of blood withdrawn from the right elbow twenty hours before death remained sterile.

Cultures from the heart's blood, the liver and the spleen made at the autopsy remained sterile. Cultures from the peritoneal exudate gave Streptococcus and Staphylococcus pyogenes aurens in agar plates, in milk tubes and on blood-agar slants. The smears from the exudate showed only a few cocci.

Remarks.-It is to be noted that the local peritonitis was limited to the area from which the appendix and gangrenous cyst had been removed and that it was less marked at the time of postmortem than at the time of operation. Sections of the appendix and cyst showed streptococci and staphylococei.

Blood: The blood conditions during the postoperative period were as follows: The first day, Saturday, leucocytes 12,800 , the second day, Sunday, not noted. The third day, Monday, 15,200, the fourth day, Tuesday, 14,800. Evidently not especially significant.

Urine: The urinary conditions were significant. The urine was examined before the operation and found to be negative. Following this examination it was examined frequently, and found on January 23, which was Monday, to be a highly concentrated urine, with an acidity of 11.6 , containing diacetic acid, a trace of acetone and one and one-fourth (1.25) grams per liter of albumin, and a number of hyaline, granular ani waxy casts. A subsequent examination on the same day showed less albumin, no acetone and less diacetic acid. The following day, Tuesday, there was still albumin, diacetic acid and a little blood. Later in the same day it was still highly acid, with less albumin, more diacetic acid and a great deal of blood. The same day, at $3: 30$ p. m., diacetic acid was absent; the other conditions were unchanged. Later, Tuesday, the conditions were the same, but with no diacetic acid. The next day, Wednesday, the urinary conditions were much the same; there was less blood and albumin and no diacetic acid. At 9 a. m., on Wednesday, the day of death, there was the same condition of nephritis, with no diacetic acid, but a great deal of blood.

It is to be notel that her breath on Tuesday and Wednesday had a sweetish, acetone odor.

Opinions of Plysicians in the Case.--The opinions during the progress of this case were various. First, the assumption was that it was septic. Certain of the consultants had a reservation, feeling that it was some sort of autotoxic condition. A blood examination made by Dr. Hektoen during life was entirely negative.

The commentary of Dr. Patrick on the nervous manifestations particularly bearing on the question of meningitis is herewith included.

The deduction of Dr. Fektoen from his postmortem investigations is also included.

The deceptive signs indicating cardiac involvement with absolutely negative findings at autopsy are interesting.

The true nature of this experience has only unfolded itself gradually under the enlightening influence of the negative findings and an exhaustive study of the literature.

\section{REVIEW OF LITERATURE.}

'There have appeared in the literature from time to time since 1846 and $184 \%$ - the years marking the introduction of anesthetics-the reports of a number of cases resulting fatally after operations, in which anesthetics were employed. These cases presented unusual symptoms, and postmortem findings which could not be attributed to the more common causes of death after operation, such as shock, hemorrhage, sepsis, pneumonia, uremia, etc.

A certain considerable number of these obscure cases, because of the identity of symptoms and postmortem findings, evidently belong to the same group and are certainly the result of the same obscure causes.

The cases to which I refer have been reported under several headings. Guthrie ${ }^{1}$ reports nine fatal cases under the title, "Some Fatal After Effects of Chloroform on Children." Brewer ${ }^{2}$ reports a similar case as "Fatal Acetonemia Following an Operation for Acute Appendicitis." Kelly reports these cases under the title of "Acid Intoxication; Its Significance in Surgical Conditions."

Brackett. Stone and $\mathrm{I}_{0} \mathrm{w}^{3}$ report this group under the title of "Aciduria (Acetonuria), Associated With Sudden Death After Anesthesia." Other authors have reported these cases as deaths due to acute vellow atrophy of the liver. Cohn ${ }^{4}$ reports a case under title of "A Case of Protracted Effect of Chloroform, with Fatal Termination."

Stocker ${ }^{5}$ reports a case identical with our own as one

1. Guthrie, L. G. ; "Some Fatal After Effects of Chloroform on Children." Iancet, 1S94. I, pp. 193-257.

2. Brewer, G. F.; "Fatal Acetonemia Following an Operation for Acute Appendicitis." Ann. of Surg., 1902, xxxvi, p. 481.

3. Brackett. E. G., Stone, J. S., Low, H. C.: "Aciduria (Aceton. urla) Assoriated with Sndden Death After Anesthesia," Boston Med. and Surg. Jour.. 1904 , cll, p. 2.

4. Cohn. Max. "Tin Fall von protrahirter Chloroform wirkung mit todtlirhen Ausguage," Deut. Zeits. f. Chir., 1902, lxiv, p. 189.

5. Stocker: Contralbi. f. Gynäkologie, 1895, No. 45. 
of acute yellow atrophy of the liver after the twisting of the pedicle of an ovarian cyst. Without doubt many of those deaths have not been correctly interpreted, and have been regarded as deaths due to late shock, fat embolism, sepsis, meningitis, uremia, etc.

Within the last year the evidence on this subject has accumulated rapidly, and it would seem that the time has arrived when the large number of clinical reports and the experimental laboratory findings have thrown enough light on this obscure subject to warrant an attempt to analyze the evidence at hand and to determine the essential cause of death, to describe the usual symptom-complex and to determine the postmortem findings of this heretofore little understood pathologic condition. Most of us, I believe, even those of us who have had a comparatively wide experience in surgery, have felt that after the giving of an anesthetic, if the patient recovered from its immediate effects, that there were no further dangers from the anesthetic, except such well-known dangers as pneumonia and nephritis, conditions which could be recognized readily by proper means of diagnosis. We have thought little about, and paid little attention to the possibility of late obscure poisonous effects of chloroform and ether which were difficult to recognize, and frequently fatal in termination. Yet as early as 1850 , Casper ${ }^{8}$ recognized the late poisonous effects of chloroform, and in 1862 said :

It can no longer be doubted that there is such a thing as chronic poisoning by chloroform-that is, that the drug when it does kill does not always kill instantaneously. but that hours, days or even weeks may elapse during which the person anesthetized remains continuously under the influence of the poison to which he at length siccumbs.

Experimentally, the truth of Casper's statement has been proved by a number of investigators. Nothnagel, ${ }^{7}$ in 1866, proved that chloroform produced a fatty degeneration of the liver and heart muscle, when injected subcutaneously or into the stomach.

Ungar, ${ }^{8}$ in $188 \%$, showed that chloroform inhaled by animals as it is used as an anesthetic produces a fatty degeneration of various organs, especially of the liver, very similar to the fatty degeneration of the liver in phosphorus poisoning.

Strassmann, ${ }^{\circ}$ in 1889 , showed that animals weakened by loss of blood and then chloroformed showed a much more extensive fatty degeneration than those not so weakened.

In 1890, Thiem and Fischer ${ }^{10}$ reported the first case in clinical work of a man who died four days after chloroform anesthesia, in whom the postmortem showed fatty degeneration of the liver.

Bastianclli, ${ }^{11}$ in 1891 , reported three deaths occurring in from three to ten days after chloroform narcosis, without any other apparent cause. These patients presented as symptoms: Vomiting, icterus, delirium and coma, and at postmortem in one case extensive fatty degeneration of the liver was found.

Fraenkei, ${ }^{12}$ in 1892 . reported cases with careful microscopic and macroscopic studies of the changes of the internal organs after protracted chloroform nar-

6. Casper: Quoted by Guthrie, Lancet, 1903, No. II, p. 10.

7. Nothnagel : Berl. klin Worhft., 1866 , lit, 31

8. Ungar: Viertelfahrschrf. f. gerichtl. Med., 1887

8. Ungar: Vierteljahrschrf. f. gerichtl. Med., 1887.
9. Strassmann: Virchow's Arch., 1889, exv, I.

10. Thiom and Fischer: Deuts. Medizinalzeit, 1889

11. Bastlanelli, R.: "Sulla morte tardiva per chloroformlo." Bull. della societe Lancisiana deglia Ospedali di Roma, June 22, 1890, p. 325. Abstract in Rer. de Sclences Med., 1892, vol. xxxix p. 625 .

12. Frankel, A. : Virchow's Arch., 1892, Bd. 127, 129. cosis. In each case, he noted extensive changes in the liver cells, but did not attribute the death to these, as there were no symptoms definitsly pointing to the liver. after chloroformt anesthesia.

Luther ${ }^{13}$ in 1893 noted the occurrence of icterus.

Bandler, ${ }^{14}$ in 1896 , after a review of the literature up to that time, and a careful study of a case in Wölfler's clinic, came to the conclusion that chloroform under certain conditions can produce serious effects a long time after its inhalation. The effects on the heart and kidneys are well known and fairly generally recognized. The changes produced in the liver are little known and understood. He believes, however, that the liver is affected by chloroform used as an anesthetic in varying degrees from a scarcely perceptible lesion to an almost total destruction of the organ.

Bandler cites the fact that Nachod found bile in the urine after chloroform anesthesia, without any apparent icterus. He himself had found it in ten cases in which there was scarcely any evidence of icterus in the sclera. He believes that the evidence of the destructive effect of the chloroform on the liver cells is found in the cases of chloroform icterus, which are marked, but which disappear in a few days, with the recovery of the patient. He believes that the extreme degree of chloroform poisoning is found in the fatal cases of acute yellow atrophy of the liver which follow its use. an example of which he reports.

In the light of his investigation, Bandler believes that just as the heart and kidneys are carefully examined before the giving of an anesthetic, and their condition recognized as important in the choice of the anesthetic agent, so the condition of the liver, if possible, should be determined before the anesthetic, and when any liver lesion is found. chloroform should not be employed, but ether should be the anesthetic of choice. because, as he showed by animal experiments, ether does not produce the destructive effects on the liver cells found so constantly after chloroform anesthesia.

Offergeld..$^{15}$ in 1905 , in an experimental study of the poisonous effects of chloroform on the kidneys, presents some most interesting results.

Animals chloroformed for a long time (up to two hours), after recovery from the immediate effects of the anesthetic, seemed perfectly well, played about and ate. On the second day they were less lively, and not so hungry as usual. Later, they would lie down in the corner, and could be made to move about only with difficulty, and then they would at once lie down again; usually at the end of from 48 to 60 hours they were dead. A postmortem examination showed that in these animals-rabbits, guinea-pigs-after a single narcosis parenchymatous degenerations occur in the heart, liver and kidneys, which produce death after a short time, even though the animal has apparently stood the anesthetic well.

In a second series of experiments it was shown (a) that fatty degeneration of the kidney did not occur in the kidney which had its arterial supply cut off by ligation of the renil artery after forty minutes' anesthesia; $(b)$ that fatty degeneration of the kidney occurred in a most pronounced type after ligation of the renal vein, after thirty minutes' anesthesia; (c) that fatty degeneration occurred more rapidly after ligation of the ureter, even after twenty-five minutes' anesthesia.

- In a third series of experiments, in which an artificial nephritis had been produced, extensive injury was produced, even by fifteen-minute anesthesia.

13. Luther: Klin. Zeit. In Streit fragen, 1893.

14. Bandler, v.: "Ueber den Einflusz der. Chloroform und Aethernarkose auf die I eber." Mittiel, aus den Grenzgebelt der Med., 1896 , Bd. 1, p. 303.

15. Offergeld: "Experimental Beltrag z. toxischen Wirkung des Chlorolforms auf die Nieren." Arch. f. klin. Chir., 1905, vol. Ixxv, p. 758 . 
In a fourth series the kidneys were injured by mineral acid and mercury, and then short-ten, fifteen and twenty-minute -anesthesias were found to be followed by death and the usual fatty degenerations.

In a fifth series the kidneys were injured by pus germs, and it was shown that a nephritis greatly favored fatty degeneration after chloroform narcosis.

In another group diphtheria toxins were injected into the animals, with the result that it was shown that the kidney inflammation produced by these poisons furnished an excellent soil for the development of fatty degeneration after chloroform narcosis.

In a sixth series, in which pregnant animals were employed, it was found that pregnancy in itself did not favor fatty degenerations, but that pregnancy complicated with kidney lesions did.

In a seventh series animals which had recovered from a prerious short anesthesia were again chloroformed, and it was found that the fatty degeneration produced by the first anesthesia favored greatly the intense injury of the kidneys from a second anesthesia.

In an eighth series an effort was made to ascertain the effect of diet, and the conclusion was reached that after chloroform narcosis the urea in the presence of a nephritis is irregular in amount.

In a ninth series, after twenty-minute anesthesias on a num. ber of animals on the same day, one was killed each day, and it was found that regeneration is possible.

In a tenth series the conclusion was reached that after chloroform narcosis fat disappears in the tissues and accumulates in the liver, so that the percentage of fat increases in the liver, while it decreases in the other organs.

In an eleventh series the conclusion is reached that the anesthesia produced by chloroform and oxygen does produce degenerative changes in the kidney, but only to a limited degree. and in a few days complete recovery follows.

Offergeld experimented a little with ether, but found that most of his animals died, even after from thirty to sixtyminute anesthesias, of pneumonia.

Oflergeld believes that there is a certain idiosyncrasy in regard to chloroform and that some individuals can take amounts without injury which would produce extensive degenerations in another. He points out the importance of the knowledge that anemic and cachectic conditions of the patient favor the poisonous action of chloroform, and also the dangers of repeated anesthesias following closely one after the other.

offergeld found constantly in his experiments that the most marked change at death was found in the liver. He came to the conclusion, however, that death is due to the production of a nephrolysin resulting from the effect of the chloroform on the kidney cells.

Offergeld believes that the prevention of this ill effect of chloroform may be accomplished by the use of a mixture of chloroform and oxygen.

Under the title of fat metamorphosis in the internal vital organs after simple and mixed narcosis, Benno Miiller ${ }^{16}$ this vear reviews much the same ground. Muiller made fifty animal experiments. with the usual anosthetios. His conclusions are as follows:

1. Anesthesia with chloroform, chloral hydrate, bromethyl and chlorethyl, ether and mixtures of these always produce changes in the internal organs, which appear as beginning fatty changes.

2. Fatty changes occur also in the epithelium of the respiratory trict.

3. The fatty changes in degree and extent depend on the time and number of the anesthesias.

4. The power of the various anesthetics to produce fatty changes is in direct proportion to their anesthetic power.

16. M:Iler, R. : "Weher Fettmetamorphose in den inneren faren chym lebens wichtige Organen nach Einfachen u. MIuch narkosen." Archiv. f. klin. Chir., 1905, No. Ixxv, p. 876.
5. These fatty changes usually disappear shortly after the anesthesia. If a second anesthetic, however, is given before the fatty changes of the first have been recovered from, the effects of the second are enhanced and the cells become ne. crotic.

It makes little difference when the second anesthetic is given, the fatty changes after the second are twice as severe as from the first.

6. The anesthetic continues to produce fatty changes as long as it is present in the blood. The fatty changes can not go on to restoration to normal until the blood has freed itself from the last vestige of the drug.

7. It is hazardous to give a second anesthetic within three days after the first, and the anesthesia should be as short as possible.

8. Pneumonia occurs frequently after ether and ether mixtures; because of a possible pneumonia after anfirst ether anesthesia, one should choose chloroform for a seetond.

9. Each anesthetic produces after long use an increase in the mucous secretion. One finds in the lung after each anesthesia small areas filled with mucus (not infected pneumonic areas), which very soon disappear, but which are greatly increased by a second anesthesia inside of from twenty-four to forty-eight hours.

10. Chloral hydrate forms chloroform in the system.

11. The mixed anesthesias have no property of prevention of fatty changes in the internal organs.

12. Every anesthetic produces fatty changes in the vessel walls of the brain, and in the ganglion cells up to a certain stage and in the other internal organs.

\section{THE CLINICAL SIDE.}

With the assistance of Dr. Dean D. Lewis, we have collected from the literature 27 fatal cases after anesthesia, making with our own 28 , which from symptoms and postmortem findings belong, we believe, to the same group. In two cases reported in the literature the patient recovered:

Bastianelli reported 3 cases; Bandler, 1 case; Ballin, 1 case; Brackett, Stone and Lcw, 3 cases; Brewer. 1 case; Cohn, 1 ease; Erlach, 1 case; Guthrie, 14 cases; Kelly, 1 case; Marthen, 1 ease; Stocker, 1 case; Mintz, 1 case; Bevan and Favill, 1 case. Total, 30 . Chloroform was einployed in 23 cases; ether in 4 cases; Billroth mixture in 1 case; not stated, 2 cases. Total 30 .

We summarize below the essential facts in each case: Bastianelli, ${ }^{11}$ in 1890 , reports 3 cases in which death occurred on from the third to the tenth day following the use of chloroform. In two of the patients vomiting was frequent and profuse. The patients were icteric and restless. Just before death they became comatose. Autopsy revealed a fatty degeneration of the heart, kidneys and liver. The fatty changes in the latter organ were most marked in the center of the lobule and resembled closely those found in other poisoning, especially phosphorus.

The original article was not accessible, and no statement can be made concerning the age, sex and predisposing causes.

These are probably the first cases reported and published of true late chloroform poisoning. Thiem and Fischer published somewhat earlier the autopsy findings in a patient dying four days after chloroform, but this case must be accepted with some reserve, as it is regarded by Fraenkel as delirium tremens.

Guthrie, in 1894, reports the clinical histories of ten patients; nine died and one recovered. The autopsy findings in eight fatal cases are given:

CASE I.-Male child, aged 3, under the care of Mr. Watson Cheyne, was operated on in 1887 for vesical calculus. There were no predisposing causes. Chloroform was used as an anesthetic. Two and one-half hours after the operation the chill was restless. Vomiting was noted at this time. Eight hours after operation the chíld repeatedly uttered piercing shrieks, tossed about in bed, and was sweating profusely and was cold. 
Death occurred suddenly ten hours after operation. Screaming continued until a few hours before death.

Autopsy.-Lungs and liver normal; spleen slightly enlarged; kidneys, both in early stages of granulation, congested; capsule somewhat adherent. Brain congested, but no evidence of inflammatory changes in meninges.

CASE 2.-Female child, aged 7, under the care of Mr. Stanlev Boyd. Anemia possible predisposing cause. An excision of the knee joint was done under chloroform anesthesia. The carbolic acid spray was used. Patient was collapsed after the operation. Four and one-half hours after the operation the child began to vomit incessantly. Shrill screams were uttered. the restlessness finally passed into coma, and death resulted twelve hours after the operation.

Autopsy.-The pelves of both kidneys contained pus. All other organs appeared normal.

CAse 3.-Female child, aged 4, under the care of Mr. Watson Cheyne, was operated on for double genu valgum. Chloroform was used as an anesthetic. The operation lasted about one hour. No predisposing causes. Vomiting commenced about five hours after operation. The child became delirious; the delirium alternating with apathy. Child screamed constantly. Temperature rose to 102, just before death, which occurred twenty-seven hours after operation.

Autopsy.-The liver was found somewhat pale and greasy. Kidneys and spleen were normal. The heart muscle was pale, but not fatty. There was considerable venous congestion in the brain; otherwise normal.

CASE 4.-Male child, aged 1 year 4 months. Service of Mr. Watson Cheyne. Carbolic-acid intoxication may have been predisposing cause. Operation was done for congenital hydrocele under chloroform anesthesia. Lengthy operation. Excessive vomiting was noted soon after operation. Death occurred twenty-four hours after completion of operation.

Autopsy-Liver large, firm and pale. Microscopically, fatty infiltration.

CAse 5.-Male child, aged 4. Service of Mr. Stanley Boyd. Operation for correction of double talipes equino varus, resulting from infantile paralysis. Chloroform anesthesia. Symptoms began thirteen hours after operation. Vomiting was frequent and profuse. Child soon became unconscious. Just before death temperature rose to 101 . Death occurrer thirty hours after operation.

Autopsy.-Ijiver small, weighing $141 / 2$ ounces; microscopically, two-thirds of the external portion of the lobule was fatty. There was intense fatty infiltration, perhaps unaccompanied by fatty degeneration.

Case 6.-Female child, aged 8 . Service of Mr. Stanley Boyd. Carbolic-acid intoxication was possible predisposing factor. Operation for double genu-valgum; lasted one hour and ten minutes. Chloroform anesthesia. The symptoms were vomiting, restlessness and coma. Death occurred fifty-three hours after anesthetic.

Autopsy.-Liver small, weighing 1 pound 3 ounces.

CASE 7.-Female child, aged 4, well nourished and apparently healthy. Service of Mr. Stanley J3oyd. Chloroform anesthesia; chloroform taken badly. Iliac abscess was opened and 2 ounces of 10 per cent. iodoform glycerin emulsion were injected. Collapse after operation. The symptoms were inressant romiting: child either apathetic or extremely restless and delirious. Carboluria noted. Death occurred six days after operation. Temperature shortly before death reached 104.6 .

No autopsy permitted.

CASE 8.- Female child, aged 2. Service of Mr. Watson Cheyne. Child was apparently in good health; iliac abscess was opened under chloroform. Anesthesia lasted about fifteen minutes, and one-half ounce of chloroform was taken well. Twelve hours after operation the child was dull and apparently in shock. Death occurred fourteen hours after operation.

Autopsy.-Peritoneum congested. Some fluid found about abscess. "No apparent cause of death."

CASE 9.-Female child, aged $81 / 2$. Service of Mr. Watson Cheyne. No predisposing cause. Psoas abscess was opened under chloroform and irrigated with $1-4,000$ bichlorid solution.
The child was pale and restless after operation. The symptoms were severe abdominal pain, nausea and vomiting; diarrhea with some blood in stools. Temperature 95.8. The symptoms persisted for three days, then abated, and recovery followed. Judging from the character of the symptoms and the use of bichlorid in the operation, it seems that mercurial poisoning should be considered in this case.

CaSE 10.--Female child, aged 4. Service of Mr. Pollard. Operation under chloroform for double psoas abscess and spinal caries. Operation lasted about one hour. Symptoms were noted four hours after operation. Child was very restless, calling for water; flushed; pulse full. Sixteen hours after operation child was restless, with wild look; temperature 103. Death occurred sixteen hours after operation.

Autopsy.-Liver large and pale; fatty on section. Kidneys soft and pale (postmortem). Tuberculous glands about root of lung; one had ulcerated into root of lung. Calcareous tubercles in lung. Caries of body of third lumbar vertebra.

(To be continued.)

\section{OSSIFICATION OF THE LOWER JAW IN MAN.* \\ EDWARD FAWCETT, M.B. (EDIN.) \\ Professor of Anatomy, University College. BRISTOL, ENGLAND.}

From the fact that there are so many different accounts given of the ossification of the lower jaw, it is evident that the question is in need of reinvestigation. Nothing more recent than Pland-Sutton's account seems to have been published on the subject, and that is based on work apparently done in $1883^{1}$ and, as will be seen, it can be by no means considered conclusive.

It is necessary to state the various accounts as the recognized text-books give them in order to appreciate the great diversity of opinion which exists.

If we begin with Quain, we find the following statement:

The largest part of each half is formed from a deposit (dentary) in the membrane on the outer side of Meckel's cartilage, and to this there is added a second smaller plate (splenial) which forms the inner walls of the tooth sockets, term:inating behind in the lingula. A small part of the body by the side of the symphysis results from the direct ossification of the anterior end of Meckel's cartilage; and, nos. teriorly, the condyle and a portion of the ramus, including the argle, are developed from anotler ossification in sartilage.

\section{Macalister ${ }^{2}$ says :}

One center of ossification begins in the embryonic tissue around Meckel's cartilage on the thirty-eighth day. A supplen:ental patch of cartilage appears in this tissue at the angle and a second at the condyle. Centers of ossulication, condyla: and angular arise in each of these patches, and a third in the median end of Meckel's cartilage; a fifth or splenial center arises in the lingula. These all very rapidly unite, so that by the fourteenth week but one bony uniss is present on each side.

Kollman, ${ }^{3}$ who quotes Toldt, ${ }^{4}$ Stieda; and Schafer, ${ }^{6}$ says that the anlage of the lower jaw can be seen in an embryo of $30 \mathrm{~mm}$. from neck to tail. The ventral site of union of both Meckel's cartilages is surrounded by bony lamellæ which arise, not out of cartilage, but out of mesoderm and develop upward, following Meckel's car-

- Read in the Section on Stomatology of the American Medical Associatlon, at the Fifty-sixth Annual Session, July, 1905.

1. Trans. Odont. Soc.

2. Text-book of Anatomy, p. 242.

3. Entrickstungsgeschichte des Menschen, p. 261.

4. Toldt: Zeitft. d. Heilk. Vol. $\mathbf{1}, 1884$.

5. Stleda : Arch. f. mikroskop. Anat., vol. $1 f_{2} 1875$

6. Schaffer: Arch. f. mlkroskop, Anat., vol. sxxii, 1888. 